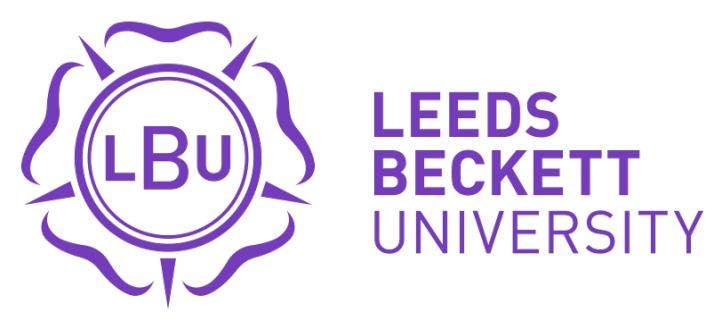

Citation:

Sampaio, AR and Thomas, $R$ and Font, $X$ (2012) Why are Some Engaged and Not Others? Explaining Environmental Engagement among Small Firms in Tourism. International Journal of Tourism Research, 14 (3). 235 - 249. ISSN 1099-2340 DOI: https://doi.org/10.1002/jtr.849

Link to Leeds Beckett Repository record:

https://eprints.leedsbeckett.ac.uk/id/eprint/278/

Document Version:

Article (Submitted Version)

The aim of the Leeds Beckett Repository is to provide open access to our research, as required by funder policies and permitted by publishers and copyright law.

The Leeds Beckett repository holds a wide range of publications, each of which has been checked for copyright and the relevant embargo period has been applied by the Research Services team.

We operate on a standard take-down policy. If you are the author or publisher of an output and you would like it removed from the repository, please contact us and we will investigate on a case-by-case basis.

Each thesis in the repository has been cleared where necessary by the author for third party copyright. If you would like a thesis to be removed from the repository or believe there is an issue with copyright, please contact us on openaccess@leedsbeckett.ac.uk and we will investigate on a case-by-case basis. 
This is the pre-peer reviewed version of the following article: Sampaio, A.; Thomas, R.; Font, X. (2011). Why are some engaged and not others? Explaining environmental engagement among small firms in tourism. International Journal of Tourism Research, which has been published in final form at http://onlinelibrary.wiley.com/doi/10.1002/jtr.849/pdf.

\title{
WHY ARE SOME ENGAGED AND NOT OTHERS? EXPLAINING ENVIRONMENTAL ENGAGEMENT AMONG SMALL FIRMS IN TOURISM
}

Ana Sampaio

Centre for Geographical Studies, P.T.

Rhodri Thomas

Leeds Metropolitan University, U.K.

Xavier Font

Leeds Metropolitan University, U.K.

\begin{abstract}
This paper examines the reasons for different levels of environmental engagement among small firms in tourism. Drawing on theories of motivation, notably Social Cognitive Theory, Motivation Systems Theory and Goal Orientation Theory, as well as the literature on environmental sensitivity, it proposes a novel conceptual framework that is subsequently used to inform an empirical study. The findings of the research suggest that varying levels of environmental engagement may be explained by differences in worldviews, levels of self-efficacy beliefs, context beliefs and goal orientation. The paper concludes by considering the policy implications of the results.
\end{abstract}

Keywords: environmental engagement, small tourism businesses, personal agency beliefs, goal orientation, worldviews.

\section{Introduction}

Academics and policy-makers have been interested for some time in finding ways of encouraging small businesses to act in more environmentally sensitive ways. In developed countries, this has resulted in a raft of initiatives that are remarkably similar in their approach, almost regardless of their particular geographical context. Perhaps the most common feature of policy has been an emphasis on voluntary participation in schemes that are generally justified by reference to some kind of business case; crudely, they are usually presented as cost saving 'win - win' scenarios (2007). This means demonstrating cost savings for the enterprise if they adopt particular kinds of environmental practices rather than requiring them to do so via regulation (Leslie, 2007; Tzschentke, Kirk \& Lynch, 2008; Halme \& Fadeeva, 2000).

A particular conceptualization of small businesses underlies such approaches. In official circles, they are usually seen as rational utility-maximising agents. Such a perspective has been undermined by academic research over the past decade or more which has shown that business motivations are complex, heterogeneous and probably vary over time (Getz \& Carlsen, 2005). Common explanations for the limited participation in voluntary schemes 
tends to revolve around market failure, lack of time, limited financial resources and/or inadequate skills for implementing and maintaining environmental management systems (Gerstenfeld \& Roberts, 2000).

This paper starts from the premise that conceptualising small businesses in tourism as rational economic agents has severe limitations when seeking to understand the factors that influence environmental engagement. 'Environmental engagement' is used here to mean the business response to environmental issues, including their reasoning and motivation for managing and adopting environmental practices. An approach is proposed which utilises theories of motivation to focus on the relationship between beliefs and goals, and actions as a potentially productive way of explaining different levels of environmental engagement (Eccles \& Wigfield, 2002; Pajares, 1997). The study should be seen as building on the work of others who have already demonstrated the importance of values in small business decision-making (for example, Ateljevic and Doorne, 2000). Dewhurst and Thomas (2003) also emphasised the need to examine values and used, with mixed success, Ajzen and Fishbein's (1980) theory of reasoned action to cast light on how values and a range of other factors influence practice. Their recognition of the need to differentiate between businesses resulted in a suggested categorisation which, in turn, implied the need for different kinds of stimuli to encourage engagement. Tzschentke et al.'s (2008) more recent work confirmed the critical role played by values and the need to understand the social context of decisionmaking.

\section{Personal agency beliefs, goal orientation and worldviews}

Theories of motivation such as Motivation Systems Theory, Social Cognitive Theory, and Goal Orientation Theory focus specifically on the articulation of actions with beliefs, values and goals, and have been widely applied in education, management and health (Eccles \& Wigfield, 2002; Pajares, 1997). In Motivation Systems Theory, personal agency beliefs represent the patterning of individuals' perceptions of ability (self-efficacy beliefs) and context responsiveness (context beliefs) (Ford, 1992). With regard to Social Cognitive Theory, self-efficacy beliefs are one of the mechanisms that govern the cognitive self-regulation of motivation and performance attainments (Bandura, 1997; Wood \& Bandura, 1989). Self-efficacy beliefs are defined as: “(...) beliefs in one's capabilities to organize and execute the courses of action required to produce given attainments" (Bandura, 1997, p.3).

In terms of environmental practices, self-efficacy beliefs would, therefore, influence levels of confidence to undertake activities such as identifying damaging business activities, keeping up-dated records and to find funding for aiding the implementation of environmental practices. Context beliefs refer to the perceived importance of the particular circumstances to facilitating individuals' personal goals (Ford, 1992). A responsive context in this case might be access to sound guidance (e.g. advice), resources (e.g. local facilities for recycling), and social support (e.g. guests supporting their environmental commitment).

Goal orientation may be useful as part of an explanation of why individuals prefer to engage in certain tasks and activities, notably by focusing on learning (mastery goal orientation) or performing (performance goal orientation) (Pintrich, 2000). This concept has been used to explain preferences and strategies for approaching and managing tasks (Zimmerman \& Schunk, 2004; Pintrich, 2000; Seijts, Latham, Tasa \& Latham, 2004). Applied to environmental engagement, understanding goal orientation may provide a way of assessing 
owner-managers' propensity to learn and willingness to participate in challenging environmental tasks (mastery goal orientated) or to engage only in familiar environmental tasks where success is more certain (performance goal orientated).

Personal agency beliefs and goal orientation are envisaged as mediators, i.e. regulatory factors, of environmental engagement. Perceptions of individual ability (self-efficacy beliefs) and context responsiveness (contexts beliefs) contribute to regulating what might be seen as attainable. Thus, personal agency beliefs are an aid to understanding engagement because they intervene in the activation of behaviour. For example, self-efficacy beliefs may influence the type of practices pursued and performance. Those practices, for a small business owner who is not confident of having the skills and ability needed for their implementation, may be diverted to other actions perceived to be easier to achieve. Even in a responsive context, perceived as congruent with personal goals (high context beliefs), those doubting their ability are arguably more resistant to changing their behaviour or to engaging in unfamiliar tasks.

Moreover, they may lower their effort or disengage from activities when experiencing higher stress levels. Conversely, very confident people may be more resilient to failure and more willing to set and be committed to difficult goals (Wood \& Bandura, 1989). Goal orientation may help to conceptualise the general orientation towards managing environmental practices. Those with a desire to learn while doing, may be more actively engaged in implementing environmental practices and more willing to adopt unfamiliar challenging practices. Conversely, those who are performance orientated would be less concerned with learning; they would be more willing to adopt familiar practices in which they perceive themselves as being more able and successful (Dweck \& Legett, 1988).

The level of engagement in sustainability issues have also been associated with individuals' worldviews (Molnar \& Mulvihill, 2003). Worldviews are defined as individuals' perceptions, understandings and assumptions about physical and social reality (Nonaka, 1994); cognitive representations of the prior experiences which provide a framework that enables individuals to reduce the world's complexity (Rosner, 1995). Worldviews influence cognition and behaviour, notably in perceiving and comprehending new data, forecasting, and remembering and manipulating information in problem-solving (Mezirow, 2009; Doyle $\&$ Ford, 1998). Hence, worldviews guide action and provide meaning to life (Yalaki, 2004). Environmental sensitivity, defined as the individuals' empathetic view of the environment, has been recognised in the literature as a pre-requisite of environmentally-friendly behaviour (Hungerford \& Volk, 1990).

The environmental sensitivity literature may be helpful in explaining the influence of worldviews in environmental engagement. Hence, practices adopted may be influenced by outdoor experiences of nature, role models such as parents, and vocational experiences (Chawla, 1999). However, the development of environmental sensitivity may be better envisaged as the result of interpretations of those experiences and how they have become significant in informing the adoption of environmental practices (Chawla, 1999). These life experiences may then influence worldviews with regards to environmental issues and, consequently, the environmental practices adopted.

\section{Study Methods}


The research adopted a mixed-method approach, based on quantitative and qualitative enquiry. All small businesses involved in the research were members of the sustainability certification Green Tourism Business Scheme; in operation since 1997, with over 1400 members across the UK in 2006, doubled by early 2010 . This ecolabel was chosen to ensure that the businesses investigated had voluntarily adopted environmental practices to some extent and could be distinguished according to the range and type of practices adopted. The scheme assesses each business on up to 60 measures (out of 150 individual measures) in order to determine a membership level (e.g. Bronze, Silver, or Gold) (GTBS, 2010). Primary research was conducted in Scotland, since this is where the scheme has been operating for the longest. The research focused on owner-managers because the management process of small businesses is highly personalised and depends on the owner-manager's managerial competence and experience, notably when solving problems and making decisions (Beaver, 2002; McKercher, 1998; Walley, 2000).

The quantitative stage of the research encompassed the development of a self-completion questionnaire, including demographic and business variables, as well as four scales context beliefs, self-efficacy beliefs, mastery goal orientation and performance goal orientation - measured on a seven point Likert-scale. The questionnaire was pilot tested and mailed to 194 small accommodation businesses. The survey had a response rate of $54.1 \%$, consistent with other small business surveys (Hall \& Rusher, 2004). The sample is consistent within the survey population in terms of type of business (prevalence of Bed \& Breakfast businesses), regional distribution (prevalence of the Highlands of Scotland region) and ecolabel awards (prevalence of Silver awarded businesses).

Likert-scale items were defined as ordinal variables because most items were not normally distributed (Morgan, Leech, Gloeckner \& Barrett, 2004). Scale reliability and unidimentionality were obtained by an iterative sequence of deleting items with low interitem and item-to-total scores; also, recomputing Cronbach alphas and item-to-total correlations was carried out, together with factor analysis, until the maximum internal consistency and unidimentionality of the scale could be identified. Principal components analysis using a varimax (orthogonal) rotation explored underlying dimensions in scale and item loadings.

Cluster analysis maximised the heterogeneity between the cluster and the homogeneity of the respondents within the clusters. Conversely to factor analysis, cluster analysis is used to assess the structure and classify objects (e.g. respondents, products) instead of variables (Hair, Anderson, Tatham \& Black, 1998). Stem-and-Leaf Plot and Boxplot revealed ten outliers, excluded to not affect the structure of the clusters, resulting in 81 cases for analysis. Tolerance values were above 0.2 and variable inflation factors were below five. The five variables used in the cluster analysis were not highly correlated. Non-hierarchical cluster analysis (k-means method) was performed using a factor (k) of three and delivered three consistent groups (inclusive model), consistent with the hierarchical analysis solution. The clusters' solution was validated by discriminant analysis, based on the assumption of homogeneity of variance-covariance (Kinnear \& Gray, 2006). Complementary Chi-square tests of the demographic (gender, age, level of qualification) and business variables (e.g. type of accommodation, business health and ecolabel award level) were conducted.

The qualitative element of the research, which followed, enabled investigation of critical events in the development of individuals' behaviour, explaining their environmental actions (Chawla, 1999; 2006). The qualitative enquiry encompassed nine case studies of 
owner-managers that had participated in the survey, but were not intended to belong to a particular group emerging from the quantitative analysis, as the qualitative enquiry focused on exploring the influence of worldviews and not in establishing a correspondence with the patterns of environmental engagement that are dynamic and may evolve with time.

Face to face in-depth interviews took place in the "natural setting" of the case (Yin, 2009) and were the main source of qualitative data. The questionnaire responses, working files supplied by the ecolabel, and observation of the business by staying there as a guest were used for the purposes of triangulation (Patton, 2002; Yin, 2009). Documents corroborated and/or supplemented other sources, mostly leaflets, general information on display or provided by the owner-manager (e.g. copy of seminar presentations); informal conversations with the owner-managers and other guests, as well environmental information concerning the business (e.g. "green file"; guest book) were also recorded. Site audit reports undertaken by the ecolabel were used to identify practices adopted and to enhance the interpretability of interview data.

\section{Patterns of environmental engagement}

The cluster analysis revealed three different groups with similar beliefs (context, ability) and preferences (goal orientation) about managing environmental practices. The final cluster centres are displayed in Table 1 and the distances between the final clusters in Table 2. The final clusters were interpreted as follows: very high mean values (above 0.5) correspond to very high scores on the seven-point Likert scale and, therefore, are more pessimistic, whereas very low mean values (below -0.5 ) represent more positive opinions. Mean values close to zero were interpreted as indicating a moderate opinion (Maroco, 2003).

The three cluster groups diverge in their personal agency beliefs and goal orientation, especially with regards to the importance given to the contextual factors helping them to adopt environmental practices, self-efficacy beliefs and a desire to learn. Cluster I classifies $20(24.7 \%)$ owner-managers as "self-centred" because of their strong performance orientation. They have moderate 'likelihood belief', low 'enable belief', high 'self-efficacy belief', very low 'performance goal orientation' and very high 'mastery goal orientation'. This is interpreted as being moderately optimistic about the responsiveness of the context in facilitating their adoption of environmental practices, having low confidence in their ability to manage environmental practices and being very performance goal orientated. Therefore, they seem to prefer to engage in familiar rather than unfamiliar (challenging) tasks when there is a need to acquire ability.

Cluster II is the second largest comprising 27 (33.3\%) owner-managers. They are the only group with positive cluster centres and higher mean values in all variables; indicating more pessimistic opinions and are, therefore, labelled as "sceptical". This means that they are pessimistic about the context responsiveness and have little confidence in their ability to manage the environmental management activities stated in the scale (e.g. to overcome unexpected problems). Moreover, they do not appear particularly interested in either proving or acquiring new skills when managing environmental practices. The third and final cluster - the self-confident - is the largest group, comprising 34 (42.0\%) owner-managers. In contrast to cluster II, these have negative cluster centres in terms of their context beliefs, self-efficacy, and mastery goal orientation. Thus, they are the most optimistic about the context responsiveness and their ability to undertake environmental practices; while they 
prefer to master (acquire ability) and engage in challenging unfamiliar practices. This results in distinctive patterns of environmental engagement with the self-confident being more actively engaged (more prone to engage in unfamiliar practices) when compared to self-centred and sceptical owner-managers.

The distances between the final cluster centres (Table 2) indicate that the second (sceptical group) and the third (self-confident) clusters are the most dissimilar, having the largest distance (2.68), with the sceptical and self-centred group being the most similar. Chi-square results indicate non-statistically significant differences across the clusters for gender, age and level of qualification. However, proportionally, there are more females (70.0\%) in the self-centred group than males $(30.0 \%)$; with the sceptical group having more males $(63.0 \%)$ and the self-confident group contains the same proportion of females and males. Statistically significant differences amongst the clusters are only identified for the variable "ecolabel award", but not number of staff, type of accommodation or business health (Table $3)$.

This means that the level of performance in the ecolabel, indicative of the range and depth of practices adopted, is dependent on the owner-manager's level of optimism, confidence and desire to learn. Therefore, the self-centred group characterised by having little confidence and desire to learn encompasses mainly businesses with a Bronze award (45\%), whereas the self-confident group are the reverse, with only nine percent having received this award. Although both the sceptical and self-confident groups have received mainly Silver awards (above 40\%), they diverge in their second most representative award. The Gold award is the least represented in the sceptical group (18.5\%), whereas the self-confident group (41.2\%) has more businesses that have won this award than the remaining groups. A more nuanced analysis of these groups is presented below.

Table 1. Final cluster centres (mean values)

\begin{tabular}{lccc}
\hline Variables & $\begin{array}{c}\text { Cluster I } \\
\text { Self-centred } \\
\text { owner-managers }\end{array}$ & $\begin{array}{c}\text { Cluster II } \\
\text { Sceptical } \\
\text { owner-managers }\end{array}$ & $\begin{array}{c}\text { Cluster III } \\
\text { Self-confident } \\
\text { owner-managers }\end{array}$ \\
\hline $\begin{array}{l}\text { Enable beliefs } \\
\text { Likelihood } \\
\text { beliefs }\end{array}$ & -.34 & 1.02 & -0.61 \\
$\begin{array}{l}\text { Self-efficacy } \\
\text { beliefs }\end{array}$ & .05 & .57 & -0.48 \\
$\begin{array}{l}\text { Performance } \\
\text { goal orientation }\end{array}$ & -.44 & .70 & -0.81 \\
$\begin{array}{l}\text { Mastery goal } \\
\text { orientation }\end{array}$ & .83 & .51 & 0.03 \\
\hline \multicolumn{1}{c}{$\mathbf{n}(\%)$} & $20(24.7 \%)$ & $27(33.3 \%)$ & $34(42.0 \%)$ \\
\hline
\end{tabular}


Table 2. Distances between the final cluster centres

\begin{tabular}{cccc}
\hline Cluster & $\begin{array}{c}\text { I } \\
\text { (Self-centred) }\end{array}$ & $\begin{array}{c}\text { II } \\
\text { (Sceptical) }\end{array}$ & $\begin{array}{c}\text { III } \\
\text { (Self-confident) }\end{array}$ \\
\hline I & & 2.03 & 2.19 \\
II & 2.03 & & 2.68 \\
III & 2.19 & 2.68 & \\
\hline
\end{tabular}

Table 3. Chi-square test results

\begin{tabular}{|c|c|c|c|c|}
\hline \multirow[b]{2}{*}{ Variables } & \multicolumn{3}{|c|}{ Clusters n (\%) } & \multirow[b]{2}{*}{ Chi-square test } \\
\hline & $\begin{array}{c}\mathbf{I} \\
(\text { Self-centred })\end{array}$ & $\begin{array}{c}\text { II } \\
\text { (Sceptical) }\end{array}$ & $\begin{array}{c}\text { III } \\
(\text { Self-confident })\end{array}$ & \\
\hline \multicolumn{4}{|l|}{ Gender } & \multirow{3}{*}{$\begin{array}{c}\chi^{2}=5.003 \\
p \text {-value }=0.08 \\
\mathrm{H}_{0} \text { not rejected }\end{array}$} \\
\hline Female & $14(70.0)$ & $10(37.0)$ & $17(50.0)$ & \\
\hline Male & $6(30.0)$ & $17(63.0)$ & $17(50.0)$ & \\
\hline \multicolumn{4}{|l|}{ Qualification } & \multirow{3}{*}{$\begin{array}{c}\chi^{2}=4.251 \\
p \text {-value }=0.12 \\
\mathrm{H}_{0} \text { not rejected }\end{array}$} \\
\hline Non-academic & $12(66.7)$ & $8(34.8)$ & $16(53.3)$ & \\
\hline Academic & $6(33.3)$ & $15(65.2)$ & $14(46.7)$ & \\
\hline \multicolumn{4}{|l|}{ Number of staff } & \multirow{3}{*}{$\begin{array}{c}\chi^{2}=2.804 \\
p \text {-value }=0.25 \\
\mathrm{H}_{0} \text { not rejected }\end{array}$} \\
\hline$\leq 2$ & $16(80.0)$ & $18(66.7)$ & $19(57.6)$ & \\
\hline$>2$ & $4(20.0)$ & $9(33.3)$ & $14(42.4)$ & \\
\hline \multicolumn{4}{|c|}{ Type of accommodation } & \multirow{3}{*}{$\begin{array}{c}\chi^{2}=1.956 \\
p \text {-value }=0.38 \\
\mathrm{H}_{0} \text { not rejected }\end{array}$} \\
\hline Bed \& Breakfast & $9(45.0)$ & $16(64.0)$ & $21(61.8)$ & \\
\hline Self-catering & $11(55.0)$ & $9(36.0)$ & $13(38.2)$ & \\
\hline \multicolumn{4}{|l|}{ Business Health } & \multirow{3}{*}{$\begin{array}{c}\chi^{2}=1.746 \\
p \text {-value }=0.42 \\
\mathrm{H}_{0} \text { not rejected }\end{array}$} \\
\hline Good & $12(75.0)$ & $16(66.7)$ & $18(56.3)$ & \\
\hline Very Good & $4(25.0)$ & $8(33.3)$ & $14(43.8)$ & \\
\hline \multicolumn{4}{|l|}{ Award Level } & \multirow{4}{*}{$\begin{array}{c}\chi^{2}=11.502 \\
p \text {-value }=0.02 \\
\mathrm{H}_{0} \text { rejected }\end{array}$} \\
\hline Gold & $5(25.0)$ & $5(18.5)$ & $14(41.2)$ & \\
\hline Silver & $6(30.0)$ & $12(44.4)$ & $17(50.0)$ & \\
\hline Bronze & $9(45.0)$ & $10(37.0)$ & $3(8.8)$ & \\
\hline
\end{tabular}

Note: The null hypothesis $\left(\mathrm{H}_{0}\right)$ is that there are no differences between the distributions among the three clusters (Maroco, 2003). If $\mathrm{H}_{0}$ is not rejected, this means that the distribution between the groups is independent of the variable. The null hypothesis is rejected when the $p$-value $<0.05$. 


\section{Self-centred.}

Performance goal orientated individuals are stated in the literature as focusing mainly on the self and being successful in performance outcomes (Pintrich, 2000); higher levels of commitment would be shown under familiar and easier environmental practices, rather than in novel ones. Conversely to mastery goal orientated, these individuals would not perceive novel practices as opportunities to acquire knowledge and, therefore, would not be willing to invest time and effort in adopting those practices. Task difficulty, low self-efficacy beliefs and fear of failure may prevent engagement (Darnon, Butera \& Harackiewicz, 2007). This behaviour poses difficulties when agencies attempt to encourage adoption of new practices. Nicholls (1989) observes that the specific task, the setting and the social context may encourage the use of mastery goals, associated with learning. Agencies could benefit from identifying and focusing on familiar practices for further improvement; while perceived unfamiliar practices may be encouraged by providing settings and social contexts to induce a mastery goal orientation. Therefore, beyond a performance context provided by the schemes' awards, the focus should probably be directed at aiding the process of managing those unfamiliar practices. This study provides some insight into the environmental management practices this group perceives themselves as less able to perform.

Although self-centred owner-managers find it important to network with other businesses, they doubt their ability to network for environmental purposes and to find tailored advice to their needs. A possible explanation may be due to their lack of confidence in identifying damaging environmental business activities and overcoming unexpected problems when attempting to adopt new practices. Consequently, they prefer to engage in tasks they perceive as being successful. Hence, this may explain the limited range of environmental practices adopted and the prevalence of Bronze awards in this group. These findings parallel Wood \& Bandura (1989) and Dweck (1988), where lower self-efficacy (perception of ability) and mastery orientation (desire to learn) were found to restrict individual's career options, lower their commitment, be highly vulnerable to change, be more likely to visualise failure scenarios and low persistence. Hence, seemingly defensive behaviour towards environmental practices may be perceived as a sign of a lack of confidence instead of environmental carelessness. This may aid in explaining the inadequacy of self-claimed environmental attitudes as a reliable indicator of engagement and enactment.

Self-centred owner-managers are more dependent on external aid. However, support organisations need to develop activities and "messages" that enhance self-confidence and desire to learn. Relating new practices to those more familiar and easier to manage would probably facilitate this situation. The self-centred group includes owner-managers adopting a wider range of environmental practices (30\% Silver and $25 \%$ Gold awards). Since these performance orientated individuals tend to focus their efforts on familiar practices, it is possible to envisage those businesses as having adopted most of these practices (now encouraged by the ecolabel) prior to joining the scheme. Hence, it seems clear that engagement may be affected by the goals (mastery vs. performance) pursued whilst managing environmental practices. Those being performance orientated would mainly focus their attention on adopting familiar practices and stick to what they know best. Getz et al. (2004) labelled these owner-managers as the "defenders", characterised by not taking risky decisions. 
Sceptical.

Research indicates that individuals with lower self-efficacy beliefs and mastery and performance goal orientation restrict their range of action, have lower commitment and goals, a lower sense of control over potential threats, are more likely to visualise failure scenarios and are highly vulnerable to change (Meece, 1994; Wood \& Bandura, 1989; Dweck \& Legett, 1988). Indeed, Meece's (1994) study on the role of motivation in selfregulated learning identified that students with lower mastery-performance goal orientation had the lowest self-efficacy beliefs for science, resulting in lower intrinsic motivation for engagement in learning science and in higher use of effort-minimisation strategies. Lower personal agency beliefs and mastery-performance orientation makes individuals least willing to engage in continual environmental improvement. Failure to adopt environmental practices would probably result in withdrawal and reinforce disbelief in their personal capacity. The sceptical group fits within this description.

Together with the self-centred group, sceptical owner-managers are expected to be less willing to continually improve, notably based on unfamiliar practices. These two groups are the most closely related; both exhibit a lower sense of self-efficacy and desire to learn. Strategies to encourage adopting unfamiliar practices may be similar to those described for the self-centred, with additional attention to building trust through contextual factors these owner-managers believe more relevant in aiding their environmental management.

Sceptics are more doubtful about their capacity to undertake "Plan-Check-Act" practices such as identifying environmentally damaging activities and keeping up-dated records. This conflicts with the managerial format proposed by Green Tourism Business Scheme that encourages an environmental management systems approach. Sceptics may be receptive to improving practices already in place that are meaningful to them, but would be less responsive to more administrative/monitoring tasks (e.g. keeping up-dated records). As a voluntary scheme, only practices promoted by the ecolabel perceived as convenient to make their business more manageable would be endorsed. The pessimistic outlook of the sceptical owner-managers contrasts with the optimism of the self-confident group, presented next.

\section{Self-confident.}

Individuals with higher personal agency beliefs and mastery goal orientation are stated in the literature as being more intrinsically motivated and actively engaged in learning activities (Meece, 1994; Dweck \& Legett, 1988; Wood \& Bandura, 1989). Wood et al. (1989) revealed that individuals with higher self-efficacy beliefs have a wider range of actions, set higher goals for themselves, show higher commitment to these goals, are more persistent and have greater perseverance, which generally leads to higher achievements. Robust beliefs of their own capability to attain tasks could be a consequence of interpreting past endeavours as successful. The self-confident group fits within this description. These owner-managers are more intrinsically motivated and would be more willing to adopt unfamiliar practices. Therefore, the findings suggest that this group would be easier to encourage and engage in continual environmental business improvement. This may be the reason why this group has more Silver and Gold awards, having undertaken more certification measures than the remaining groups where Bronze awards prevail. One explanation for the higher awards achieved may be related to their optimism in the 
responsiveness of the context and with their confidence to undertake environmental practices.

This group also seems more likely to be willing to share their experiences with other businesses and to be actively engaged in learning and problem-solving activities. Consequently, their preference for performing challenging work and learning whilst managing environmental practices may contribute to reinforcing their knowledge and selfefficacy and, consequently, foster engagement and performance. This situation may explain their confidence in identifying environmentally damaging business activities and overcoming unexpected problems whilst managing environmental practices.

Interestingly, these do not engage mainly in tasks where success is certain. Some do not appear very concerned about making errors because, as mastery orientated individuals, they perceive it as part of their learning. Also, they show enough confidence to believe that they will succeed whilst adopting unfamiliar practices. The high incidence of Gold awarded businesses $(41.2 \%)$ may be linked to their perceived capacity for engaging in challenging work, allowing them explore and adopt a wider range of practices. These findings are aligned with literature suggesting that mastery and performance goals may interact, leading to higher engagement and achievements (Meece, 1994). Hence, self-confident owner-managers are more likely to be positive towards engaging in unfamiliar practices although the strategies applied (effort vs. effort-minimizing strategies) may vary across the different types of practices because they are also moderately performance goal orientated. Therefore, although more receptive to challenging work, self-confident owner-managers will also be responsive to familiar practices.

In comparison with the other groups, self-confident owner-managers are characterised by their positive outlook towards their capacity to achieve. The perception of having a responsive context (e.g. family support, recycling facilities) and high confidence in the adoption of environmental practices may then aid the setting of higher environmental targets. As pointed out by Ford (1992, p.133), "this is the most motivationally powerful pattern (...) because people with strong capability beliefs and positive context beliefs maintain their expectation that their goals will ultimately be achieved even in the face of obstacles." Conversely to the sceptical group, it is possible to argue that the self-confident share a similar environmental vision to the one encouraged by the ecolabel; this may be important for envisaging prescribed environmental practices as personally meaningful goals. The development of this shared vision may result from their perceived ability to do "Plan-Check-Act" practices such as identifying environmentally damaging businesses activities and keeping up-dated records, as well as problem-solving.

The discussion above has explored different patterns of environmental engagement. It is also instructive to consider how worldviews are also enmeshed in an explanation of different levels of environmental engagement.

\section{Worldviews and environmental engagement}

Worldviews are perceptions and convictions that provide a framework for action (Rosner, 1995). For this purpose, environmental sensitivity, defined as an empathetic view of the environment, has been recognised as a pre-requisite for environmentally-friendly behaviour (Hungerford \& Volk, 1990). A number of authors identified the positive influence of experiences in natural areas and adult role models in childhood (e.g. family, educators, and 
mentors), environmental organisations, education, negative experiences of environmental degradation, books, media and job experiences as influencing environmental career choice, activism, environmental concern or interest (Chawla, 1998; Chawla, 1999; Palmer \& Suggate, 1996). Therefore, previous research suggests that the development of an environmental sensitivity arises from combined life experiences and events.

The qualitative research undertaken for this project confirmed this and showed how sources of environmental sensitivity (Table 4) may encompass being brought-up in the countryside, role models (family), observing countryside destroyed, vocational experiences, participating in environmental-related organisations and moving to the countryside. Positive life experiences seem associated with different stages of life, although those in childhood (e.g. positive experiences in nature; cohort effect and family role models) appeared crucial to develop a vision of the environment. Some evidence suggests that environmental sensitivity evolves in adulthood mainly because of vocational experiences, participation in organisations, observation of environmental degradation and moving to the countryside.

Table 4. Sources of environmental sensitivity

\section{Positive experiences in natural areas}

Positive experiences in nature during childhood: being brought-up in the countryside, enjoyment of outdoor activities in natural settings, such as free play in fish ponds;

Positive experiences in nature during adulthood: walking, cycling, hands-on outdoor activities, such as growing one's own vegetables;

Work experiences on a farm: raising animals and organic vegetables.

\section{Influential experiences, events and people}

Upbringing experiences: cohort effect where parsimonious habits were developed; exposure to family values and behaviour (e.g. father as a role model);

Motherhood experience: concern for children and grandchildren with the desire to provide good living conditions; acquisition of parsimonious habits because of economic constraints;

Organisations: observation of the increased currency of environmental issues in organisations (e.g. local council, Quality Assurance, Local Chambers of Commerce); participation in environmental organisations and schemes (e.g. GTBS, farming schemes);

Media: news of environmental destruction; observation of programmes with examples of good practice;

Moving to the countryside during middle adulthood in search of quietude and unspoiled environment; Involvement in community projects (e.g. hydro-electric project) where there are opportunities to network and a need for learning about environmental issues;

Vocational experiences: deepening of environmental concerns; development of skills and outlook applied in environmental management (e.g. efficiency); observation of environmental destruction; observation of good environmental business practices;

Children and friends: socialisation that has promoted the development of feelings and increased awareness towards environmental issues (e.g. discovery of environmental issues through daughter);

Environmental destruction of the countryside: fear of the destruction of a childhood or special place.

Consistent with much of the literature on small firms in tourism, not all of the ownermanagers were primarily motivated financially. Some appeared to not place much importance on cost saving opportunities in the ecolabel's audit reports. Conversely, on-thejob experiences may have contributed to the development of an economically orientated 
reasoning, which some use in their business and environmental management approach. These cases seemed to adopt the "good for business" and "good for the environment" reasoning and, therefore, appeared more responsive to practices contributing to cut running costs (e.g. monitoring, energy-efficient appliances). Owner-managers tended to accept more readily information and feedback from the ecolabel and other information sources that was consonant with their worldviews than those that conflicted with their reasoning.

Environmental Sensitivity. Environmental sensitivity has been defined as individuals' affective understanding/view of the environment or as a predisposition to take an interest, feeling or concern and to act to conserve it on the basis of formative experiences (Hungerford \& Volk, 1990). Monroe (2003) reports how research in environmental sensitivity and significant life experiences explains strategies to "cultivate" pro-environmental behaviours. Chawla's (1998) review highlights positive experiences in natural areas, adult role models (family), negative experiences of environmental degradation, books, media, and on-the-job experiences as the factors believed to influence behaviour.

The investigation into owner-managers' worldviews, in particular their sources of environmental sensitivity, mirrors the results of previous research in environmental education. This research extends the environmental sensitivity and tourism literature by suggesting that the predisposition to adopt environmental practices is in part explained by factors such as positive experiences in natural areas, vocational experiences, events and role models (e.g. family), which have influenced individual perceptions and interest for the "environment".

Positive experiences in nature, notably nature-based play in childhood, have been stated as fostering environmentally-friendly behaviour (Monroe, 2003). Particularly, Palmer et al.'s (1996) study revealed childhood outdoor experiences in the countryside as a relevant source of environmental sensitivity. The same pattern can be identified amongst most of the owner-managers studied. The findings suggest that those brought-up in rural settings or developing farm-related activities, direct their attention to practices (e.g. to buy fruit in season, to enhance garden wildlife) reflecting their proximal experiences with the "environment" (e.g. directly observing the effect of weather on the fruit seasons, affective contact with wildlife). When extending those proximal experiences into domestic operations, these owner-managers would identify themselves more readily with those practices that reflected learned principles.

Buying local and organic produce, seasonal fruit, collecting rain water, feeding birds, constructing a pond in a garden, designing a wildlife walk in a farm and recycling are perceived as more relevant for protecting what they understand as "the environment" (e.g. wildlife, trees, air quality, quality of life) than checking and recording energy consumption in detail. This is because outdoor experiences in rural areas (Kals et al, 1999). This supports Kollmuss et al.'s (2002) observation that it is essential to recognise the importance of the emotional connection with the environment in shaping individuals' perceptions towards it. This environmental connectedness, as labelled by Blanchet-Cohen (2008), reflects how owner-managers explore and relate with their surroundings on an emotional level (Chawla, 1998; Chawla, 1999; Palmer \& Suggate, 1996; Blanchet-Cohen, 2008).

Personal interpretations of these significant experiences provide meaning to everyday actions and may be considered as learning experiences. As Mezirow (2009) observes, 
learning is a new or revised interpretation of the meaning of one's experience in order to guide future action. Therefore, owner-managers' environmental sensitivity seems in part a result of learning, i.e. making meaning of life experiences in nature. Accordingly, some carry more personal investment and attach personal value (e.g. satisfaction, selfdevelopment) to those measures that involve close experiences with nature. These experiences contribute to what Ford (1992) designates as within-person goals: affective (e.g. happiness, entertainment); cognitive (e.g. gaining knowledge); and subjective goals (e.g. spiritual sense of connectedness, harmony and oneness with people and nature).

In this respect, the qualitative findings suggest that some of the measures adopted (e.g. growing one's own vegetables) were endorsed because they were enjoyable and gave high levels of satisfaction. Moreover, practices that were related to "experiencing nature" were not perceived as providing any economic gains or competitive advantage to the business (e.g. recycling, growing one's own vegetables, providing information about local walks, designing wildlife walk); these practices contributed to the non-economic goals that are generally pursued by "lifestyle" businesses.

These findings are particularly important because they may help to explain why some still engage in practices that do not involve economic gains and may neglect cost-saving opportunities of some practices (e.g. energy conservation practices). For some interviewees, adopting environmental practices was not a business (i.e. financial) issue but a personal one. This non-economic worldview is extended to the management of the business whereby non-economic goals such as guest experience, involvement in the local community, time with family and farm-related activities (e.g. taking care of cattle) were also pursued.

The consequence of this non-economic worldview consists of not attaching greater personal significance to cost-saving measures. Consequently, these owner-managers are less inclined to adopt these practices. For example, in contrast with cases that have proactively invested in replacing all traditional bulbs with energy saving ones, those with more informal/organic managerial approaches would only replace the traditional bulbs with energy saving ones once they stopped working; here, environmental performance evolves in ad hoc and small incremental steps. This is consistent with the adaptive mode described by Mintzberg (1973) and with the behaviour displayed by Getz's "defenders", who engage mainly in familiar and convenient alternatives. Therefore, some owner-managers tend to engage in manageable environmental practices that do not challenge their lifestyle goals and business bottom line.

The results draw attention to the role of positive experiences in nature for the development of a personal vision of "environment" and of an affective vision of nature, leading to argue that personal interpretations of these experiences aid the development of meanings about environmental issues and the self. This may explain why in some cases the adoption of environmental practices seems guided by a non-economic worldview. This worldview is particularly apparent in those priming within-person and non-economic business goals. However, other factors may influence environmental reasoning; additionally to positive experiences in nature, other influential experiences, events and role models are central in "cultivating" environmental sensitivity. Mezirow (1991) observes that a life event (e.g. retirement, children leaving home) or an eye-opening discussion may induce the alteration of previous beliefs, assumptions and perception of the world. Additionally, Chawla (1999) observes that participation in organisations, work experiences and concern for the future of children and grandchildren were the most prevalent factors in influencing environmental sensitivity in adulthood. 
The data from the interviews also highlights the importance of influential people and events; motherhood for one interviewee explained the redirection and intensification of action regarding environmental practices, while for another it was an environmental meeting that triggered childhood memories, supporting Yalaki's (2004) notion that individuals' worldviews may evolve in changes of life circumstances or through a desire to explore new ones, or what Mezirow (1991, p.167) defines as "perspective transformation": "(...) is the process of becoming critically aware of how and why our assumptions have come to constrain the way we perceive, understand and feel about our world (...) making choices or otherwise acting upon these new meanings". As Grusec et al. (2000, p.2009) observe, "children may also come to see a parent's way of acting as part of a natural or moral order, rather than as something that can be readily reflected on, negotiated or questioned." Children are then exposed to parents' patterns of socialisation that may be displayed in the form of routines and cultural practices (Grusec et al., 2000). We also noticed children's environmental sensitivity impacting on adults' behaviour, resulting from interaction and socialisation with what Mezirow (1991) designates as "significant ones".

Vocational experiences, notably business management, appear to influence a more economic vision. Interviewees' management and financial backgrounds coloured expectations from environmental practices; here, activities such as monitoring energy/water consumptions and keeping records were familiar routines prior to joining the ecolabel. These interviewees were more receptive to win-win messages (i.e. good for the business and environment) voiced by the ecolabel. Halme et al.'s (2000) suggestion of encouraging environmental engagement through advertisement of win-win benefits is more pertinent to these cases because this message is consistent with their worldviews for the business. These cases seemed to balance non-economic (e.g. satisfaction) with economic goals (e.g. keeping the business profitability). Pursuing both goals is not new to the small tourism business literature, with accounts of balancing profitability and desire to grow with more personal goals such as promoting ideas of spirituality (Shaw \& Williams, 2004; Thomas \& Thomas, 2006; Thomas, 2007).

\section{Conclusion: Explaining difference}

The influence of worldviews, personal agency beliefs and goal orientations have been discussed in detail in this paper. Worldviews were shown to influence environmental engagement, notably in guiding the selection of practices adopted and in noticing information and messages regarding environmental issues. However, environmental practices also need to be perceived as attainable and, therefore, personal agency beliefs and goal orientation were argued to be important regulatory factors of environmental engagement and performance. Additionally, the concept of goal orientation provides a means of understanding engagement because it gives an indication of the propensity to learn whilst managing environmental practices. Differences in personal agency beliefs and goal orientation may underlie different patterns of environmental engagement. These observations do not alone explain the conditions that are likely to encourage positive environmental engagement.

Precursor (worldviews) and mediating factors (personal agency beliefs and goal orientation) may then influence and explain levels of environmental engagement. As illustrated in the diagram below (Figure 1), both precursor and mediating factors emerge from personal interpretations of positive life experiences. The research suggests that positive mastery experiences are not only important for the "environment" to become personally meaningful 
(to develop environmental sensitivity) but also to give feedback about one's capacity to act (self-efficacy beliefs), the extent to which the context is responsive in aiding performance (context beliefs) and to promote the desire to learn.

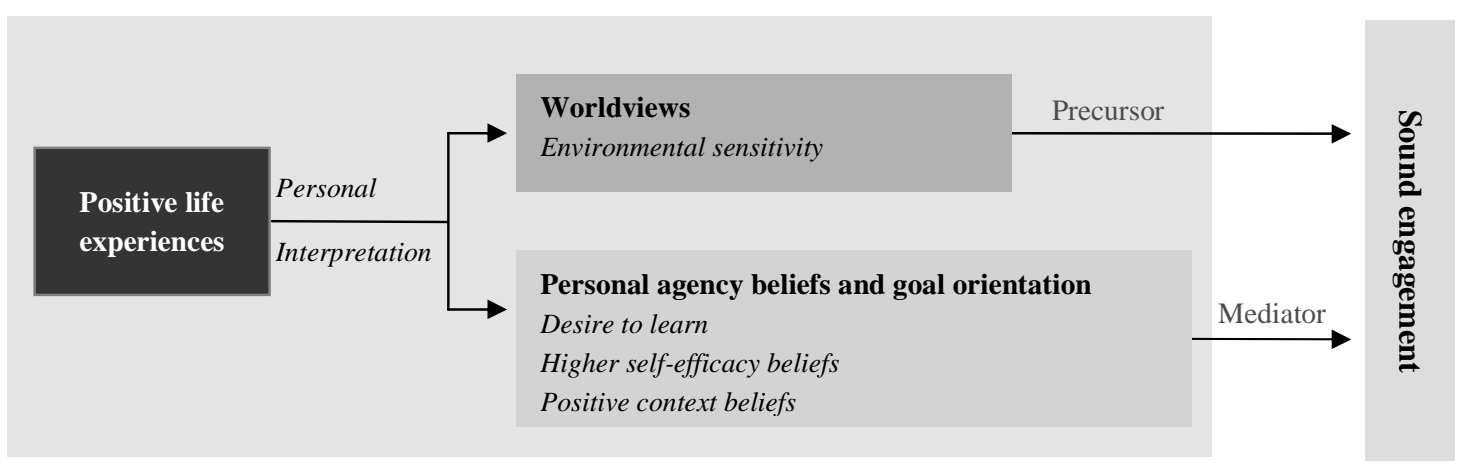

Figure 1. Conditions for sound environmental engagement

Some interviewees had childhood experiences as most significant in defining their environmental sensitivity and perceptions of personal agency, which nowadays relate to their "environmental" routines (e.g. recycling, reusing). To others their perceived selfability to keep records and to assess energy consumptions, for example, were developed through previous work and managerial experiences with a more economic than environmental meaning. Different levels of environmental engagement depend on personal interpretations of those experiences. "Making meaning" is a personal construction of experience and may be perceived as how individuals make sense of the experiences they are involved in. Thereby, behaviour is not uniform amongst individuals and experiences are open to personal interpretation (Mezirow, 2009).

This may explain the selective approach in choosing environmental practices. For those adopting a more informal management approach, being a member of the ecolabel is mainly translated into a refinement of existing practices (e.g. recycling more) or adoption of more convenient ones, rather than as an endorsement in novel and challenging practices, where personal significance is yet to be developed (e.g. monitoring energy). Thus, the extent to which those practices support the existing mental framework or affective relationship with nature without challenging the perceived capacity, i.e. the level of environmental practices familiarity, seems an important factor in guiding environmental responses. Environmental sensitivity, desire to learn, confidence in one's own capacity and a positive outlook towards the context, are some of the conditions underlying sound environmental engagement.

Looking beyond the classic external barriers stated in the literature regarding lack of resources, skills, commitment and ethics, this research points out that rigid worldviews, lack of personal agency beliefs and mastery goal orientation may be perceived as the "invisible" barriers to environmental engagement. Personal worldviews are often ignored in top-down approaches; hence, it may be necessary to build on peoples' own visions to develop a shared vision that encourages enrolment and engagement. The findings show that even businesses that have subscribed to ecolabels, however, do not "automatically" adopt the ecolabels' vision of a "green" business. It is necessary to create ways of developing a sense 
of ownership and empowerment, so that individuals can become responsible active participants.

One practical outcome of this research is that environmental programmes aiming to encourage environmental engagement should have "empowerment" as their ultimate goal. The findings of this research show that empowered (i.e. self-confident and mastery orientated) individuals were much more likely to be engaged in continual environmental improvement. By developing participative policies for empowering individuals, rather than simply selling the idea of cost savings, agencies could build the necessary conditions to nurture continual environmental business improvement that appealed to the contrasting community of small businesses in tourism.

\section{REFERENCES}

Ajzen, Fishbein 1980. In Understanding attitudes ad predicting social behaviour. Prentice-Hall International: London.

Ateljevic \& Doorne 2000. 'Staying within the fence': lifestyle entrepreneurship in tourism. Journal of Sustainable Tourism 8(5): 378-392.

Bandura 1997. In Self-efficacy: the exercise of control. W.H. Freeman: New York.

Beaver 2002. Strategy and management in the smaller enterprise. Strategic change 11:175-181

Blanchet-Cohen 2008. Taking a stance: child agency across the dimensions of early adolescents' environmental involvement Environmental Education Research 14(3):257-272

Chawla 1998. Significant life experiences revisited: a review of research on sources of environmental sensitivity. Environmental Education Research 4(4):369 - 382

Chawla 1999. Life paths into effective environmental action. Journal of Environmental Education 31(1): 15-26

Darnon, Butera,Harackiewicz 2007. Achievement goals in social interactions: learning with mastery vs. performance goals Journal Motivation and Emotion 31(1):61-70

Doyle,Ford 1998. Mental models concepts for system dynamics research. System Dynamics Review 14(1):3-29

Dweck,Legett 1988. A social-cognitive approach to motivation and personality. Psychological Review 95(2):256 - 273

Eccles, Wigfield 2002. Motivational beliefs, values, and goals. Annual Review of Psychology 53:109-132

Ford 1992. In Motivating humans: goals, emotions, and personal agency beliefs. Sage Publications: London.

Gerstenfeld,Roberts 2000. Size matters: barriers and prospects for environmental management in small and medium-sized enterprises. In R. Hillary (Ed.), Small and Medium-Sized Enterprises and the Environment: Business Imperatives (pp. 106-118). Greenleaf Publishing Limited:Sheffield.

Getz,Carlsen 2005. Family business in tourism- State of the Art. Annals of Tourism Research 32(1):237-258 
Getz, Carlsen,Morisson 2004. In The family business in tourism and hospitality. CABI Publishing: Wallingford.

Grusec, Goodnow,Kuczynski 2000. New directions in analyses of parenting contributions to children's acquisition of values. Child Development 71(1):205-211

GTBS 2010. Retrieved January 21, 2010, from the Green Tourism Business Scheme Web site: http://www.green-business.co.uk.

Hair, Anderson, Tatham,Black 1998. In Multivariate data analysis. Prentice Hall: London.

Hall,Rusher 2004. Risky lifestyles?: entrepreneurial characteristics of the New Zealand bed and breakfast sector. In R. Thomas (Ed.), Small Firms in Tourism: International Perspectives (pp. 83-98). Elsevier:London.

Halme,Fadeeva 2000. Small and Medium-Sized Tourism Enterprises in Sustainable Development Networks. Greener Management International- The Journal of Corporate Environmental Strategy and Practice (30):97-113

Hungerford,Volk 1990. Changing learner behavior through environmental education. Journal of Environmental Education 21(3):8-21

Kinnear,Gray 2006. In SPSS 14 Made Simple. Psychology Press: Sussex.

Kollmuss,Agyeman 2002. Mind the gap: why do people act environmentally and what are the barriers to pro-environmental behavior? Environmental Education Research 8(3):239260

Leslie 2007. The missing component in the 'greening' of tourism: The environmental performance of the self-catering accommodation sector. International Journal of Hospitality Management 26(2):310-322

Maroco 2003. In Análise estatística : com utilização do SPSS. Sílabo: Lisboa.

McKercher 1998. Business Development Issues Affecting Nature-based Tourism Operators in Australia. Journal of Sustainable Tourism 6(2):173-188

Meece 1994. The role of motivation in self-regulated learning. In D. Schunk \& B. Zimmerman (Eds.), Self-regulation of learning and performance: issues and educational applications (pp. 25-44). Lawrence Erlbaum Associates:New Jersey Hove.

Mezirow 1991. In Transformative dimensions of adult learning. Jossey-Bass: San Francisco.

Mezirow 2009. Transformative learning theory. In J Mezirow \& W Taylor (Eds.), Transformative learning in practice. Insights from community, workplace and higher education, (pp. 18-32). Jossey-Bass:San Francisco.

Mintzberg 1973. Strategy-making in three modes. California Management Review 16(2):44-53

Molnar,Mulvihill 2003. Sustainability-focused Organizational Learning: Recent Experiences and New Challenges. Journal of Environmental Planning and Management 46(2): 167 176

Monroe 2003. Two avenues for encouraging conservation behaviors. Research in Human Ecology 10(2):113-125

Morgan, Leech, Gloeckner,Barrett 2004. In SPSS for introductory statistics: use and interpretation. Lawrence Erlbaum: Mahwah. 
Nicholls 1989. In The competitive ethos and democratic education. Harvard University Press: Cambridge.

Nonaka 1994. A Dynamic Theory of Organizational Knowledge Creation. Organisation Science 5(1):15-37

Pajares 1997. Current directions in self-efficacy research. In M. Maehr \& P. Pintrich (Eds.), Advances in Motivation and Achievement (pp. 1-49). JAI Press:Greenwich.

Palmer,Suggate 1996. Influences and experiences affecting the pro-environmental behaviour of educators. Environmental Education Research 2(1):109-121

Patton 2002. In Qualitative Research and Evaluation Methods. SAGE Publications, Inc.: London.

Pintrich 2000. An achievement goal theory perspective on issues in motivation terminology, theory, and research. Contemporary Educational Psychology 25(1):92-104

Revell,Blackburn 2007. The business case for sustainability? An examination of small firms in the UK's construction and restaurant sectors. Business Strategy and the Environment 16(6): $404-420$

Rosner 1995. Mental models for sustainability. Journal Cleaner Production 3(1-2):107-121

Seijts, Latham, Tasa,Latham 2004. Goal setting and goal orientation: an integration of two different yet related literatures. Academy of Management Journal 47(2):227-239

Shaw,Williams 2004. From lifestyle consumption to lifestyle production: Changing patterns of tourism entrepreneurship. In R. Thomas (Ed.), Small Firms in Tourism: International Perspectives (pp. 99-114). Elsevier:London.

Thomas 2007. Tourism partnerships and small firms: power, participation and partition. Entrepreneurship and innovation 8(1):37-43

Thomas, Thomas 2006. Micro politics and micro firms: a case study of tourism policy formation and change. Journal of Small Business and Enterprise Development 13 (1):100 - 114

Tzschentke, Kirk,Lynch 2008. Going green: decisional factors in small hospitality operations International Journal of Hospitality Management 27(1):126-133

Walley 2000. What are "appropriate" systems for assessing environmental systems risks and performance in Small Businesses? In R. Hillary (Ed.), Small and Medium-Sized Enterprises and the Environment: Business Imperatives (pp. Greenleaf Publishing Limited:Sheffield.

Wood,Bandura 1989. Social cognitive theory of organizational management. Academy of management review 14(3):361-384

Yalaki 2004. In Science teachers' worldviews: a way to understand beliefs and practices. Unpublished doctoral dissertation, The Florida State University College of Education, United States.

Yin 2009. In Case Study Research - Design and Methods. Sage Publications: London.

Zimmerman,Schunk 2004. Self-regulating intellectual processes and outcomes: a social cognitive perspective. In D. Dai \& R. Sternberg (Eds.), Motivation, Emotion, and Cognition (pp. 323-349). Lawrence Erlbaum Associates:Mahwah. 